\title{
Sociobiology
}

RESEARCH ARTICLE - ANTS

\section{Leaf Volatiles from Two Corydalis Species Lure a Keystone Seed-dispersing Ant and Enhance Seed Retrieval}

\author{
Y ZHU, D WANG
}

School of Life Sciences, Central China Normal University, Key Laboratory for Geographical Process Analysis \& Simulation, Wuhan, P.R. China

\section{Article History}

\section{Edited by}

Gilberto M. M. Santos, UEFS, Brazil

Received $\quad 09$ February 2018

Initial acceptance 28 March 2018

Final acceptance 10 April 2018

Publication date 01 October 2018

\section{Keywords}

Ants; Corydalis; myrmecochory; plant volatiles; seed dispersal.

\section{Corresponding author}

Dong Wang

School of Life Sciences

Central China Normal University

Key Laboratory for Geographical Process

Analysis \& Simulation

Hubei Province, Wuhan, 430079, China.

E-Mail: 395351998@qq.com

dw@mail.ccnu.edu.cn

\begin{abstract}
It has been reported that a suit of plant traits can regulate the ant-seed interaction and subsequently affect the seed dispersal. However, the role of plant volatiles in attracting the ants for seed dispersal remains little examined. We used a Y-tube olfactometer to test behavior response of a keystone seed-dispersing ant (Pristomyrmex pungens Mayr) to leaves and seeds of five co-occurring myrmecochorous Corydalis species (C. wilfordii Regel, $C$. racemosa (Thunberg) Persoon, $C$. sheareri S. Moore, $C$. balansae Prain and $C$. incisa (Thunberg) Persoon). Of the five species, only $C$. wilfordii and $C$. racemosa leaves emits heavily volatiles. We also performed seed cafeteria experiments to assess the effect of leaf volatiles from $C$. racemosa on seed retrieval by presenting simultaneously the seeds near the fresh leaf and the leaf immersed by diethyl ether both in the field and lab. The experiment using Y-tube showed that the ants were only significantly attracted by the fresh leaves of two species, $C$. wilfordii and $C$. racemosa. The cafeteria experiments showed that ants spent less time to detect the $C$. racemosa seeds which were near the fresh leaf, and transported these seeds more quickly. This indicated that the leaf volatiles can function as an attractant for the dispersing ants, and ant preference in turn enhance the seed retrieval. The findings reveal that leaf volatiles can play an important but underestimated role in shaping the ant-seed dispersing interactions.
\end{abstract}

\section{Introduction}

Myrmecochory (i.e., seed dispersal by ants) is a common ecological interaction in nature. Ants benefit nutrition from elaiosomes attached to seeds and plants benefit from having their seeds dispersed (Beattie, 1985). The plants that rely on ant dispersal can benefit from interaction in several ways, including directed dispersal, distance dispersal, fire avoidance and seed predator avoidance (Beattie, 1985; Giladi, 2006). Myrmecochorous plants have evolved some features, which referred to dispersal syndromes, to increase the probability and effectiveness of seeds being transported by ants. To date, diverse features of plants such as elaiosome size and chemistry (e.g., Hughes \& Westoby, 1992; Gammans et al., 2006), seed morphology (e.g., Nakanishi, 1994), predispersal mode (e.g., Nakanishi, 1994; Giladi, 2006), plant stature (e.g., Leal et al., 2015), the timing of seed release (e.g.,
Oberrath et al., 2002; Boulay et al., 2007; Arandarickert \& Fracchia, 2012), and spatial dispersion of seeds (e.g., Gorb and Gorb, 2000), have been reported to influence the association between seed-dispersing ants and myrmecochorous plants.

Many plants emit volatile organic compounds (VOCs) from most parts of their anatomy (Baldwin, 2010). The volatiles, functioning as either a deterrent to defend them against herbivores and pathogens or an attractant to lure pollinators and seed dispersers, are presumed to serve as cues that mediate various interactions with animals (Inui et al., 2003; Raguso, 2008; Unsicker et al., 2009; Baldwin, 2010). Previous studies found that ants which are involved in interactions with plants, such as protective ant-plant interaction (e.g., Brouat et al., 2000; Edwards et al., 2007) and ant-flower interaction (e.g., Wanjiku et al., 2014; Vega et al., 2014), could respond to the VOCs from host plants.However, it is stillless known about the role of volatiles in ant-seed 
dispersal interactions (Sheridan et al., 1996; Youngsteadt et al., 2008). The few existing results remain inconsistent (Borges, 2015), with ants being attracted by seed odor of Antgarden (AG) plant in Amazonian rainforests (Youngsteadt et al., 2008), but not for the myrmecochorous seeds Asarum canadense (Sheridan et al., 1996).

Apart from odor-induced seed retrieval by ants, volatiles from vegetative parts such as leaves can also mediate the interaction between ants and plants (Brouat et al., 2000; Pichersky \& Gershenzon, 2002). Until now, whether volatiles from vegetative organs such as leaves can attract the dispersing ants and such the effect of attractiveness it may has on subsequent seed retrieval remains largely unclear. The Corydalis (Papaveraceae) is a north-temperate genus with about 465 species, about 357 of which are distributed in China (Zhang et al., 2008). The species of Corydalis have elaiosomes attached to seeds to attract ants (Lengyel et al., 2010). Of them, some species can readily emit volatiles from vegetative organs, whereas others do not (Wu et al., 1999; Zhang et al., 2008). We hypothesized that (1) leaf volatiles of Corydalis can function as an attractant for keystone seed-dispersing ant, and (2) the resultant attractiveness would influence seed collection.

\section{Methods}

\section{Study organisms}

In this study, five Corydalis species including $C$. wilfordii, C. racemosa, C. sheareri, C. balansae and C. incisa were used. All the five species are ant-dispersed plants, and they co-occur in temperate forests at the margins of Mufushan Mountains $\left(31^{\circ} 49^{\prime} \mathrm{N}, 113^{\circ} 55^{\prime} \mathrm{E}\right)$, Hubei province, China. Of them, only $C$. wilfordii and $C$. racemosa emit heavily volatiles, especially the leaves (Wu et al., 1999; Zhang et al., 2008). The leaves are still present on the fruiting plants of all five species.

\section{Olfactometer Assay}

To test the behavior response of ants to leaves and seeds from the five studied species, we conducted olfactometer assay by using Y-tube olfactometer. Our previous study showed that the Pristomyrmex pungens Mayr (Formicidae: Myrmicinae) was a keystone seed disperser of Corydalis species in the study site (Zhu \& Wang, 2014). The olfactometer was a Y-shaped glass tube with a $2.6 \mathrm{~cm}$ diameter and each of the three arms $10 \mathrm{~cm}$ in length. Air flow of $750 \mathrm{ml} / \mathrm{min}$ was generated with an air pump (QC-4S, China) that directed ambient air through a charcoal filter, odor source bottles before entering a Y-shaped Teflon tube that split air flow evenly between the two arms of the olfactometer. Odorant sources were placed into an odor source bottle (the other bottles was left blank), and 50-80 ant workers were induced to the basal arm. The initial choices of the first 30 different ant workers that walked into and proceeded at least $5 \mathrm{~cm}$ down the right or left arm of the olfactometer were recorded. Thirteen replicates were conducted for each treatment. The Y-tube was washed, and the two side arms were exchanged in turn for treatments and control after each replicate. The odor sources tested in the experiments were as follows: (1) Leaf of Corydalis spp. vs blank; (2) Seed of Corydalis spp. vs blank. The T-test was used to test the response of workers to the odor sources and blank.

\section{Cafeteria experiments}

To assess the effect of volatiles from leaf on seed retrieval, we used C. racemosa seeds to conduct a cafeteria experiment both in the field and lab. In the field, we assembled 20 quadrats $(1 \times 1 \mathrm{~m}) 10 \mathrm{~m}$ apart in a $4 \times 5$ grid at a site which was at least $20 \mathrm{~m}$ away from the nearest $C$. racemosa individual. Each quadrat included two seed depots $1 \mathrm{~m}$ apart. For each depot, five seeds were randomly placed near two types of leaves which mimic the presence or absence of volatiles in the field: (1) Fresh leaf; (2) Immersed leaf - leaf was immersed by diethyl ether for $8 \mathrm{~h}$ for removal of volatiles, and were then left overnight at room temperature to allow the diethyl ether to evaporate. The experiment was conducted during peak foraging periods $(0800-1100 \mathrm{~h})$. Observations lasted $12 \mathrm{~min}$, at which point the number of seeds removed from each depot was recorded.Twenty trials were conducted.

The workers of $P$. pungens could recruit workers to collect seeds of some Corydalis species directly from their dehiscing capsules (Fig 1). We collected four colonies of $P$. pungens in the field, and maintained them in the laboratory for bioassays. The colonies were reared in plaster nests $(10$ $\times 10 \times 0.4 \mathrm{~cm})$ and placed in an area $(50 \times 37 \times 8 \mathrm{~cm})$ with walls coated with Fluon to prevent ants from escaping. Each nest contained approximately $300-400$ workers and $30-40$ larvae. The laboratory temperature and relative humidity were maintained in a range from 21 to $26^{\circ} \mathrm{C}$ and approximately $36 \%$, respectively. We supplied ants with water and sucrose water (1M), and twice a week with mealworms.

In the lab, we placed simultaneously five seeds near the two types of leaves (fresh leaf and immersed leaf) on the sites which left ca. $15 \mathrm{~cm}$ to the nest entrance in the laboratory (interleaf distance ca. $20 \mathrm{~cm}$ ). Observations lasted $12 \mathrm{~min}$, at which point the number of removed seeds from each leaf was recorded. Eight trials $(4$ colonies $\times 2$ replicates) were conducted.

\section{Data analysis}

SPSS v20 (IBM, Inc.) was used for statistical analyses and the significant difference was set at $p<0.05$. Data were transformed prior to analysis when necessary. T-test was used to test the response of workers to the odor sources and blank. General linear model (GLM) was used to test the effects of leaf type on the number of removed seeds (ln-transformed) in the lab and nest identity was included in this model as a random factor. T-test was also used to test the effects of leaf type on the number of seed removals in the field. 

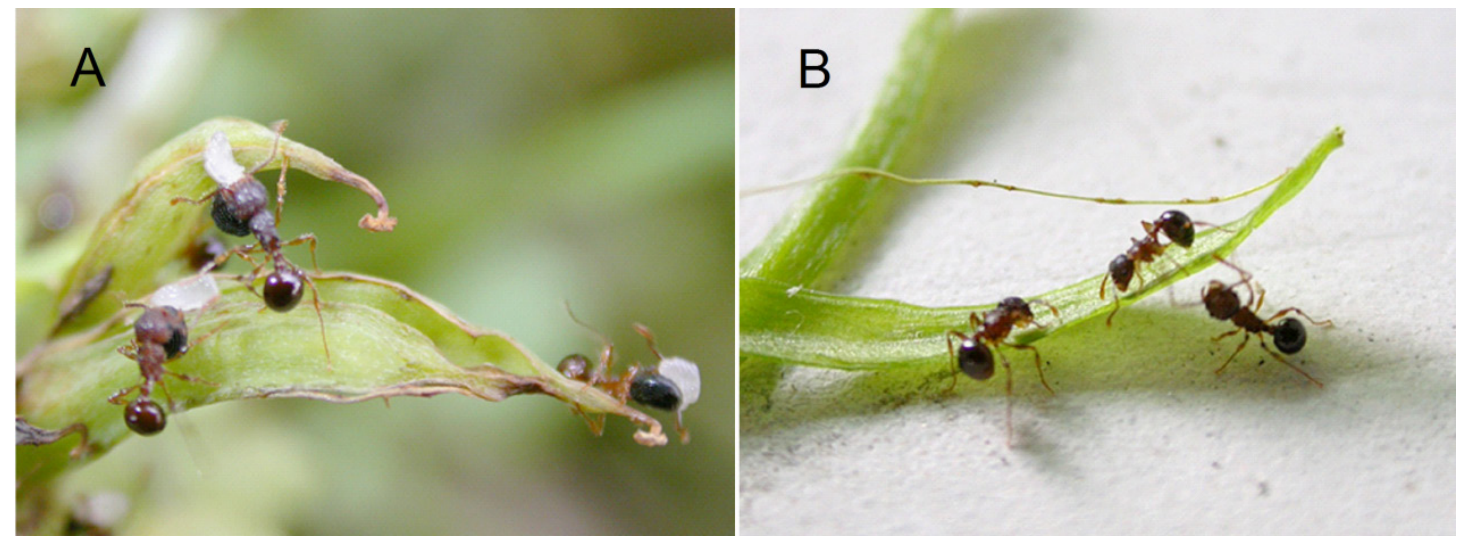

Fig 1. Workers of Pristomyrmex pungens directly collected Corydalis racemosa seeds from the dehiscing carpels in the field (A); workers were attracted by capsules of C. racemosa in the lab (B)

\section{Results}

In olfactometer assay, workers of $P$. pungens significantly preferred the arm containing leaves of $C$. wilfordii $(t=3.477, d f=24, p=0.002)$ and $C$. racemosa $(t=2.657, d f=$ $24, p=0.014)$ over the empty control arm, while workersshowed no obvious preference to leaves of the remaining three species (Fig 2A). Workers did not prefer the arm containing seeds than the empty control arm, regardless of plant identity (Fig 2B).

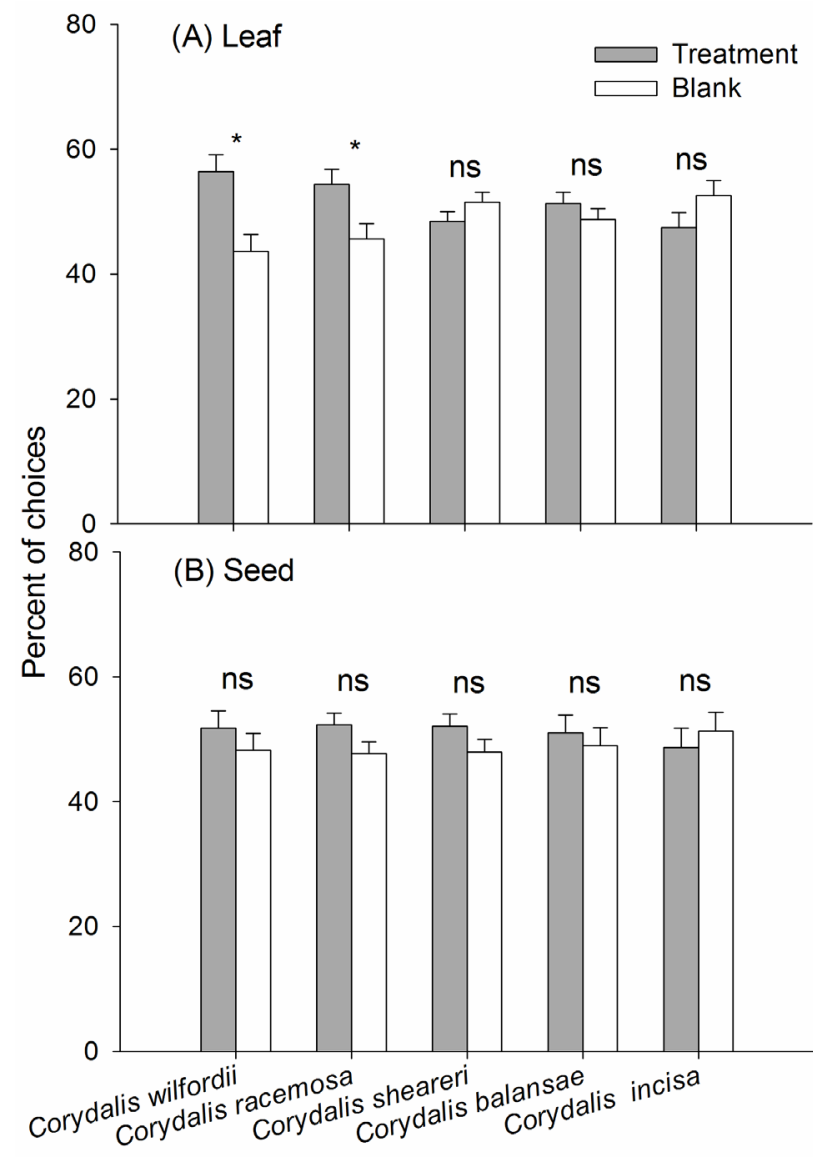

\section{Plants species}

Fig 2. Responses of $P$. pungens (mean $\pm \mathrm{SE}$ ) in a Y-tube olfactometer when given a choice between plant and clean air. (A) Leaf vs blank, (B) seed vs blank.The asterisk indicates significant difference within a choice test.
In cafeteria experiments, four species of ants were observed to retrieve seeds in the field, with $P$. pungens being responsible for the vast majority of seed removal $(73.7 \%$; Table 1). Ants located the seeds which were near the fresh leaf threefold and fourfold earlier than the seeds which were near the immersed leaf in the field and lab, respectively (Fig 3). In the field, the number of seed removals near the fresh leaf was significantly greater than that near the immersed leaf $(t=3.365$, $d f=23.235, p=0.003$; Fig 3 ). In the lab, the number of seed

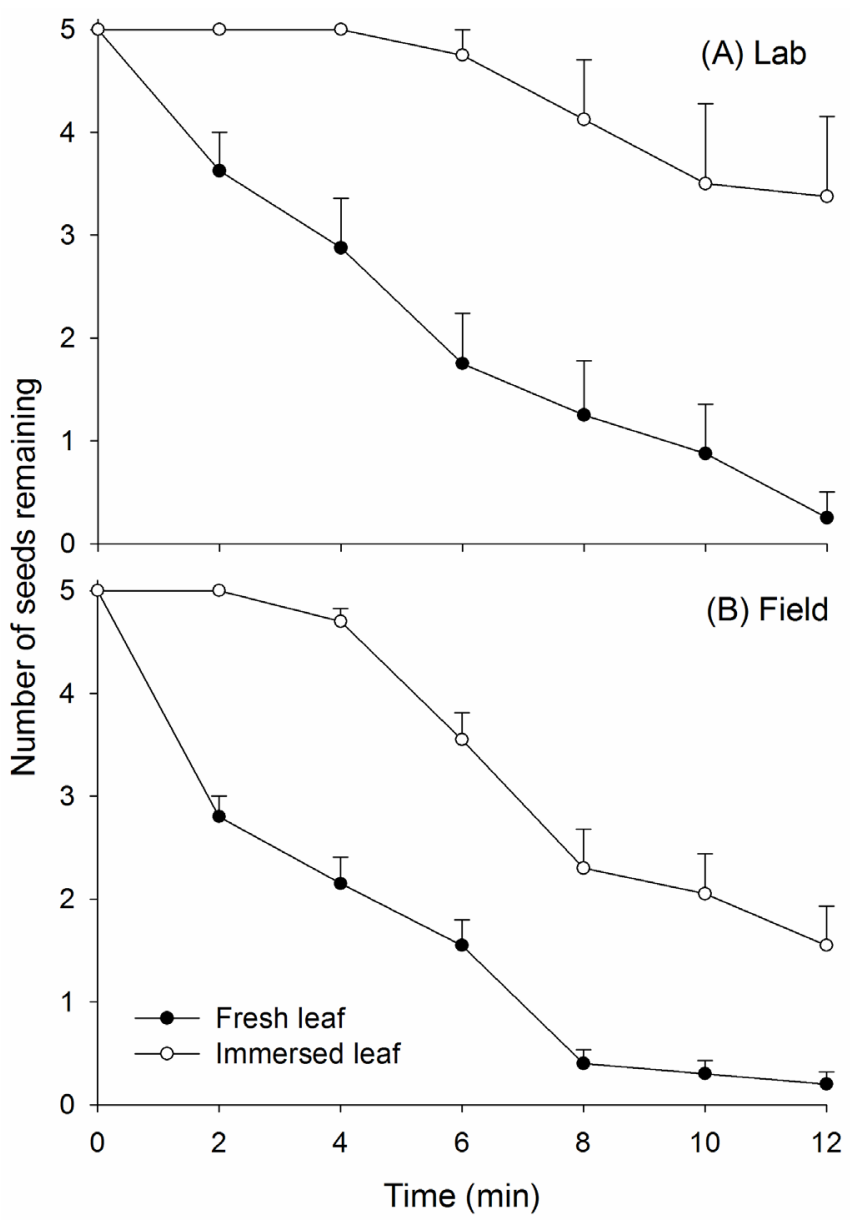

Fig 3. Number of mean seeds remaining ( $\pm \mathrm{SE})$ of $C$. racemosa in the field (A) and lab (B). 
removals near the fresh leaf was also significantly greater than that near the immersed leaf $(F=4.572, d f=1, p=0.017)$, while the nest identity had no effects on seed removals $(F=$ $1.907, d f=3, p=0.305)$. Comparing seed-removal dynamics, ants removed nearly all seeds which were near the fresh leaf after $12 \min (95 \%$ in both the field and lab), whereas they only removed $69.0 \%$ and $32.5 \%$ of seeds which were near immersed leaf in the field and lab, respectively (Fig 3).

Table 1. Number of removed seeds by each dispersing ant in the field.

\begin{tabular}{lcc}
\hline Ant species & Fresh leaf & Immersed leaf \\
\hline Pristomyrmex pungens & 74 & 36 \\
Pheidole nodus & 12 & 7 \\
Paratrechina yerburyi & 8 & 14 \\
Pachycondyla luteipes & 1 & 0 \\
\hline
\end{tabular}

\section{Discussion}

This study showed that leaf volatiles from $C$. wilfordii and $C$. racemosa can lure the keystone dispersing ants Pristomyrmex pungens, and subsequently promote the seed retrieval. Previous studies have investigated the attractiveness of volatiles to ants in the AG plant and myrmecochorous plants, and some studies found the attractiveness of seed odor to ants (Davidson et al., 1990; Youngsteadt et al., 2008), and others did not (Sheridan et al., 1996; Gammans et al., 2006; Youngsteadt et al., 2010). In the olfactometer assay, we did not observe the behavior response of $P$. pungens to seeds from the five Corydalis species, implying that the seeds may not attract dispersing ants by olfactory cues to some extent. The possible reason is that the lower volatility of compounds in the diaspores insufficiently serves as gustatory cues (Borges, 2015). Indeed, Turner et al. (2013) also reported that gas chromatography could not detect volatile chemicals from the diaspores of four typical myrmecochorous plants (i.e., Asarum canadense, Trillium grandiflorum, Sanguinaria canadensis and T. erectum).

The plants that rely on ant dispersal can benefit from interactions in several ways (Beattie, 1985; Lengyel et al., 2010). Plants may therefore evolve some dispersal syndromes to enhance seed dispersal effectiveness by ants. For example, oleic acid or its dimer diolein in elaiosome have been found to induce seed carrying behavior (Hughes et al., 1994; Pfeifferet al., 2010). The time of fruit dehiscene and seed shedding of some ant-dispersed plants at a particular moment greatly enhance the probability of seed being removed by effective seed-dispersing ants (Arandarickert \& Fracchia, 2012; Boulay et al., 2007). In the present study, ants can be attracted by volatile compounds released by both $C$. wilfordii and $C$. racemosa plants and ants could use them as chemical cue to locate the plants and, consequently, the diaspores. As a result, the presence of leaf volatiles greatly shortened the ant foraging time and increased the removal rates of seeds.
This implied that the leaf volatiles of some Corydalis species may be one important trait promoting the association between plants and ants.

Although the myrmecochorous seeds can be found and then transported by ants because of the attached elaiosome, the results of our study indicated that leaf volatiles of some myrmecochorous Corydalis species can function as an attractant for ant dispersers, and such attractiveness in turn enhances the seed retrieval. It suggests that leaf volatiles of some Corydalis species may be one of several factors shaping the ant-seed dispersing interactions. Further research is needed to identify the chemical basis of volatiles that trigger ant foraging activity, and to assess to what extent the seed dispersal of Corydalis species depend on leaf volatiles.

\section{Acknowledgements}

This research was supported by the National Natural Science Foundation of China (grant No 31170310, 31110103911), Science and Technology Basic Work (2013FY112100) and the specimen platform of China, teaching specimens sub-platform, Web, http://mnh.scu.edu. cn/ (2005DKA21403-JK).

\section{References}

Arandarickert, A. \& Fracchia, S. (2012). Are subordinate ants the best seed dispersers? Linking dominance hierarchies and seed dispersal ability in myrmecochory interactions. Arthropod-Plant Interactions, 6: 297-306. doi: 10.1007/ s1 1829-011-9166-z

Baldwin, I. T. (2010). Plant volatiles. Current Biology, 20: R392-397.doi: 10.1016/j.cub.2010.02.052

Beattie, A. J. (1985). The evolutionary ecology of ant-plant mutualisms. Cambridge: Cambridge University Press

Borges, R. M. (2015). Fruit and seed volatiles: multiple stage settings, actors and props in an evolutionary play. Journal of the Indian Institute of Science, 95: 93-104.

Boulay, R., Carro, F., Soriguer, R. C. \& Cerdá, X. (2007). Synchrony between fruit maturation and effective dispersers' foraging activity increases seed protection against seed predators. Proceedings of the Royal Society B-Biological Sciences, 274: 2515-2522.

Brouat, C., McKey, D., Bessière, J. M., Pascal, L. \& Hossaert-McKey, M. (2000). Leaf volatile compounds and the distribution of ant patrolling in an ant-plant protection mutualism: preliminary results on Leonardoxa (Fabaceae: Caesalpinioidae) and Petalomyrmex (Formicidae: Formicinae). Acta Oecologica, 21: 349-357. doi: 10.1098/ rspb.2007.0594

Davidson, D. W., Seidel, J. L. \& Epstein, W. W. (1990). Neotropical ant gardens II. Bioassays of seed compounds. 
Journal of Chemical Ecology, 16: 2993-3013. doi: 10.1007/ BF00979490

Edwards, D. P., Arauco, R. \& Hassall, M. (2007). Protection in an ant-plant mutualism: an adaptation or a sensory trap? Animal Behaviour, 74: 377-385.doi: 10.1016/j.anbehav.2006.07.022

Gammans, N., Bullock, J. M., Gibbons, H. \& Schönrogge, K. (2006). Reaction of mutualistic and granivorous ants to Ulex elaiosome chemicals. Journal of Chemical Ecology, 32: 19351947. doi: 10.1007/s10886-006-9119-7

Giladi, I. (2006). Choosing benefits or partners: a review of the evidence for the evolution of myrmecochory. Oikos, 112: 481-492. doi: 10.1111/j.0030-1299.2006.14258.x

Gorb, E. \& Gorb, S. (2000). Effects of seed aggregation on the removal rates of elaiosome-bearing Chelidonium majus and Viola odourata seeds carried by Formica polyctena ants. Ecological Research, 15: 187-192. doi: 10.1046/j.1440-1703.2000.00338.x

Hughes, L., Westoby, M. \& Jurago, E. (1994). Convergence of elaiosomes and insect prey: evidence from ant foraging behavior and fatty acid composition. Functional Ecology, 8: 358-365. doi: 10.2307/2389829

Hughes, L. \& Westoby, M. (1992). Effect of diaspore characteristics on removal of seeds adapted for dispersal by ants. Ecology, 73: 1300-1312. doi: 10.2307/1940677

Inui, Y., Miyamoto, Y. \& Ohgushi, T. (2003). Comparison of volatile leaf compounds and herbivorous insect communities on three willow species. Population Ecology, 45: 41-46. doi: 10.1007/s10144-003-0138-8

Leal, I. R., Leal, L. C. \& Andersen, A. N. (2015). The benefits of myrmecochory: a matter of stature. Biotropica, 47: 281285. doi: 10.1111/btp.12213

Lengyel, S., Gove, A. D., Latimer, A. M., Majer, J. D. \&Dunn, R. R. (2010). Convergent evolution of seed dispersal by ants, and phylogeny and biogeography in flowering plants: a global survey. Perspectives in Plant Ecology Evolution and Systematics, 12: 43-55. doi: 10.1016/j.ppees.2009.08.001

Nakanishi, H. (1994). Myrmecochorous adaptations of Corydalis species (Papaveraceae) in southern Japan. Ecological Research, 9: 1-8.

Oberrath, R. \& Böhning-Gaese, K. (2002). Phenological adaptations of ant-dispersed plants to seasonal variation in ant activity. Ecology, 83: 1412-1420. doi: 10.2307/3071953

Pfeiffer, M., Huttenlocher, H. \& Ayasse, M. (2010). Myrmecochorous plants use chemical mimicry to cheat seed-dispersing ants. Functional Ecology, 24: 545-555. doi: 10.1111/j.1365-2435.2009.01661.x

Pichersky, E. \& Gershenzon, J. (2002). The formation and function of plant volatiles: perfumes for pollinator attraction and defense. Current Opinion in Plant Biology, 5: 237-243. doi: 10.1016/S1369-5266(02)00251-0

Raguso, R. A. (2008). Wake up and smell the roses: the ecology and evolution of floral scent. Annual Review of Ecology, Evolution and Systematics, 39: 549-569. doi: 10.11 46/annurev.ecolsys.38.091206.095601

Sheridan, S. L., Iversen, K. A. \& Itagaki, H. (1996). The role of chemical senses in seed-carrying behavior by ants: a behavioral, physiological, and morphological study. Journal of Insect Physiology, 42: 149-159. doi: 10.1016/0022-1910(95)00087-9

Turner, K. M. \& Frederickson, M. E. (2013). Signals can trump rewards in attracting seed-dispersing ants. PLoS One, 8: e71871. doi: 10.1371/journal.pone.0071871

Unsicker, S. B., Kunert, G. \& Gershenzon, J. (2009). Protective perfumes: the role of vegetative volatiles in plant defense against herbivores. Current Opinion in Plant Biology, 12: 1-7. doi: 10.1016/j.pbi.2009.04.001

Vega, C. D., Herrera, C. M. \& Dötterl, S. (2014). Floral volatiles play a key role in specialized ant pollination. Perspectives in Plant Ecology, Evolution. and Systematics, 16: 32-42. doi: 10.1016/j.ppees.2013.11.002

Wanjiku, C., Khamis, F. M., Teal, P. E. A. \& Torto, B. (2014). Plant Volatiles influence the African weaver ant-cashew tree mutualism. Journal of Chemical Ecology, 40: 1167-1175. doi: 10.1007/s10886-014-0512-3

Wu, Z. Y., Zhuang, X. \& Su, Z. Y. (1999). Corydalis DC. In: Delectis Florae Reipublicae Popularis Sinicae Agendae Academiae Sinicae Edita. Reipublicae Popularis Sinicae, Tomus 32, (pp. 96-483). Beijing: Science Press.

Youngsteadt, E., Bustios, P. G. \& Schal, C. (2010). Divergent chemical cues elicit seed collecting by ants in an obligate multi-species mutualism in lowland Amazonia. PloS One, 12: e15822. doi: 10.1371/journal.pone.0015822

Youngsteadt, E., Nojima, S., Häberlein, C., Schulz, S. \& Schal, C. (2008). Seed odor mediates an obligate ant-plant mutualism in Amazonian rainforests. Proceedings of the National Academy of Sciences of the United States of America, 105: 4571-4575. doi: 10.1073/pnas.0708643105

Zhang, M. L., Su, Z. Y. \& Lidén, M. (2008).Corydalis DC. In: Wu, Z.Y., Raven, P.H., Hong, D.Y. (eds.) Flora of China 7 Menis permaceae Through Capparaceae, (pp. 295428). Beijing: Science Press, Beijing and Missouri Botanical Garden Press.

Zhu, Y. \& Wang, D. (2014). Seed dispersal of Corydalis wilfordii and C. racemosa (Papaveraceae): effect of ant foraging and behavior and seed characteristics. Acta Ecologica Sinica, 34: 4938-4942. (In Chinese with English abstract). doi: 10.5846/stxb201301010005 